Check for updates

Cite this: RSC Adv., 2017, 7, 35581

\title{
Catalytic upgrading of carboxylic acids as bio-oil models over hierarchical ZSM-5 obtained via an organosilane approach $\uparrow$
}

\author{
Kamonlatth Rodponthukwaji, ${ }^{a}$ Chularat Wattanakit, (D) *b Thittaya Yutthalekha, ${ }^{b}$ \\ Sunpet Assavapanumat, ${ }^{\mathrm{b}}$ Chompunuch Warakulwit, ${ }^{\mathrm{a}}$ Wannaruedee Wannapakdee ${ }^{\mathrm{b}}$ \\ and Jumras Limtrakulc
}

Biomass is an interesting renewable energy resource as it is widespread in nature and low cost. The development of bio-oil derived from biomass as a fuel is still a scientific and industrial challenge. In this context, we demonstrate the synthetic method of bio-oil upgrading catalysts based on hierarchical zeolites and open up interesting perspectives for bio-oil upgrading processes. The hierarchical ZSM-5 zeolite has been successfully prepared via a direct hydrothermal synthesis with the aid of a commercial organosilane surfactant (TPOAC). The influences of TPOAC content and Si/Al ratio on hierarchical structures were also systematically studied. To illustrate their catalytic performances, an esterification reaction of various organic acids such as (acetic acid and levulinic acid) and alcohols was performed as the model reaction representing the bio-oil upgrading application. The synergic effect of acidity and the hierarchical structure of catalysts can greatly enhance the catalytic performance in terms of activity, product yield, coke formation, and reusability of the catalysts. For example, they can convert almost $100 \%$ of reactant in $8 \mathrm{~h}$ in the esterification of acetic acid and alcohols, whereas the conventional zeolite reveals significantly lower activity $(<20 \%)$. Interestingly, the hierarchical zeolite can also greatly improve the catalytic activity of the esterification of levulinic acid and ethanol to produce ethyl levulinate that can be used as a diesel miscible biofuel (DMB). In addition, the efficiency of hierarchical catalysts obtained by different synthesis methods is also discussed. This first example demonstrates that the hierarchical zeolite obtained via a direct synthesis approach can benefit bio-oil upgrading applications via the esterification of various carboxylic acids.

Received 5th April 2017

Accepted 11th July 2017

DOI: $10.1039 / c 7 r a 03890 a$

rsc.li/rsc-advances

\section{Introduction}

The development of renewable energy sources has attracted a great deal of attention from both academic and industrial points of view due to the shortage of fossil fuels. Although renewable energy can be obtained from many sources, such as solar, wind, geothermal, hydroelectric, and biomass, ${ }^{1}$ the

${ }^{a}$ Department of Chemistry, NANOTEC Center for Nanoscale Materials Design for Green Nanotechnology, Kasetsart University, Bangkok 10900, Thailand

${ }^{b}$ Department of Chemical and Biomolecular Engineering, School of Energy Science and Engineering, Vidyasirimedhi Institution of Science and Technology, Rayong 21210, Thailand. E-mail: Chularat.w@vistec.ac.th; Fax: +66 33014445 extn 2176

${ }^{c}$ Department of Materials Science and Engineering, School of Molecular Science and Engineering, Vidyasirimedhi Institution of Science and Technology, Rayong 21210, Thailand

$\dagger$ Electronic supplementary information (ESI) available: Calibration curves (S1), particle size distribution (S2), XRD patterns (S3), ${ }^{27} \mathrm{Al}$ MAS NMR spectra (S4), IR spectra of pyridine adsorption experiments (S5), weight loss profiles (S6), $\mathrm{O}_{2}$ TPO profiles (S7), Raman spectra (S8), benzyl alcohol conversion (\%) on different samples obtained by different methods (S9), Tables S1-S4. See DOI: 10.1039/c7ra03890a conversion of biomass is one of the most fascinating methods because it is widespread in nature and low cost. Typically, biomass resources can be divided into one of the following three groups: (i) wastes; (ii) forest products; (iii) energy crops. ${ }^{2}$ The lignocellulosic biomass is one of the most abundant sources to be used for the production of liquid fuels or bio-oils. Although the bio-oil derived from the lignocellulosic biomass is a good candidate to replace a petroleum fuel, it typically consists of high oxygen content (20-50 wt\%) and acidity ( $\mathrm{pH}=$ 2.5-3), resulting in undesirable properties, such as low heating value, high viscosity, thermal instability, and corrosiveness. ${ }^{3}$ To overcome these problems, the upgrading of bio-oils is crucial to improve their properties. In general, the bio-oil upgrading processes can be obtained by hydrodeoxygenation (HDO), ${ }^{4}$ ketonisation, ${ }^{5}$ aldol condensation, ${ }^{6}$ and esterification. ${ }^{7}$ The most popular one is based on the catalytic upgrading via an esterification of organic acids in the presence of alcohol molecules, resulting in the reduction of oxygen content and acidity, thus improving the oil stability. ${ }^{8}$

Although a common acid catalyst, such as sulfuric acid $\left(\mathrm{H}_{2} \mathrm{SO}_{4}\right)$, exhibits an excellent catalytic activity in an 
esterification, such an acid is not recommended as it is corrosive and non-environmentally-friendly. Alternatively, various solid acid catalysts, such as sulfated zirconia, ${ }^{9}$ functionalized mesoporous silica, ${ }^{10}$ heteropoly acid, ${ }^{11}$ and zeolite ${ }^{12,13}$ have been applied. In particular, zeolites have been widely used for an esterification due to their outstanding properties, such as high surface area, high thermal/chemical stability, suitable acidity, and shape selective property.

Over the past decade, zeolites have played an important role in various potential applications, especially in petrochemical reactions, such as aromatization, ${ }^{14,15}$ isomerization, ${ }^{16,17}$ alkylation, ${ }^{18,19}$ dehydration, ${ }^{20}$ and esterification. ${ }^{21,22}$ However, the presence of sole micropores in their structures often suffers from the transportation limitation of guest molecules, including reactants, intermediates, and products. As a consequence, the catalyst deactivation can be easily observed due to the coke formation inside micropores. To improve the efficiency of a conventional zeolite, many researchers have paid a lot of effort to develop the zeolite structure by either reducing the crystal $\operatorname{size}^{23}$ or introducing the hierarchical pores into its structures. ${ }^{24-26}$ In the latter case, the fabrication of hierarchical zeolites has been successfully obtained by one of the following two major routes: (i) post-treatment, ${ }^{27-29}$ (ii) direct synthesis. ${ }^{30-37}$ In the direct synthesis, a secondary template was applied by either hard or soft templates to control the hierarchical structure. According to the soft templating approach, an organosilane surfactant has been widely used as the mesoporedirecting agent because it provides a strong interaction with the zeolitic gels, thus preventing the phase separation between zeolite precursors and mesoporous template molecules. However, it sometimes also suffers from the disadvantage because it requires many complicated steps of the synthesis of a designed organosilane template, ${ }^{38}$ while there are only a few hierarchical zeolites which have been successfully produced by using a commercial organosilane surfactant as a mesoporous structure-directing agent. ${ }^{35,39-41}$

Recently, hierarchical zeolites have been applied as an interesting catalyst for an esterification. For example, the mesoporous ZSM-5 and H-ZSM-5 monolith were prepared by an alkali treatment and using corn or sorghum stem piths as sacrificial solid templates, respectively. Interestingly, the obtained ZSM-5 can significantly improve catalytic performances of the esterification of benzyl alcohol and hexanoic acid. ${ }^{42}$ In addition, the esterification of $o$-cresol with acetic acid over mesoporous ZSM-5 zeolites obtained by an alkaline treatment or post treatment has been reported. ${ }^{43}$ The remarkably improved activity in the liquid-phase esterification of alcohol and acid was observed over the mesoporous ZSM-5 via demetallation in alkaline media.

An alternative way to produce the ordered mesoporous zeolite has been achieved by a direct synthesis or a templating approach. This strategy can obviously solve several limitations of hierarchical zeolites obtained from a post-treatment and in particular it can be used to synthesize hierarchical zeolites with a wide range of $\mathrm{Si} / \mathrm{Al}$ ratios. $^{44}$ In contrast to this, a posttreatment has been applied to the limited initial $\mathrm{Si} / \mathrm{Al}$ ratio of parent zeolites. Typically, the zeolite having the $\mathrm{Si} / \mathrm{Al}$ ratio in the range of 25-50 is the most favourable by a post-treatment, while a low mesoporosity and a loss of crystallinity are obtained in the case of higher and lower $\mathrm{Si} / \mathrm{Al}$ ratios, respectively. ${ }^{45,46}$ To the best of our knowledge, the development of hierarchical zeolites by a direct synthesis based on an organosilane approach for the bio-oil upgrading application has not yet been demonstrated, even though it is one of the most interesting alternative ways to extend the scope of hierarchical zeolite researches.

Herein, we demonstrate not only the synthesis of hierarchical ZSM-5 by a direct synthesis approach with the aid of a commercial organosilane surfactant, dimethyloctadecyl[3(trimethoxysilyl)propyl] ammonium chloride (TPOAC), as a hierarchical pore-directing agent but also its catalytic perspectives for the bio-oil upgrading application using a model reaction. The catalytic performances in terms of activity, product selectivity, and coke formation were explored via the esterification of various carboxylic acids such as acetic acid and levulinic acid and alcohols. Complementary, the reusability of hierarchical catalysts was also examined and compared with that of the conventional one. In addition, the catalytic activity of the hierarchical catalyst obtained by different synthesis methods including direct- and post synthesis approaches was discussed in details.

\section{Experimental}

\section{Preparation of catalysts}

The hierarchical ZSM-5 was hydrothermally synthesized by using the dimethyloctadecyl[3-(trimethoxysilyl)propyl] ammonium chloride (TPOAC) (42 wt\% in methanol, Sigma-Aldrich) as a mesopore structure-directing agent. For a typical procedure, we developed the synthesis method from our previous work by using the TPOAC instead of carbon material as the hierarchical mesopore-directing agent. ${ }^{47}$ In the modified mixture, a $1 \mathrm{~g}$ of silica gel $\left(\mathrm{SiO}_{2}, \mathrm{Merck}\right), 0.02 \mathrm{~g}$ of sodium aluminate (53 wt\% $\mathrm{Al}_{2} \mathrm{O}_{3}, 43$ wt $\% \mathrm{Na}_{2} \mathrm{O}$; Riedel-deHaën), $0.26 \mathrm{~g}$ of tetrapropylammonium bromide, TPABr, (98\% $\mathrm{C}_{12} \mathrm{H}_{28} \mathrm{BrN}$, Sigma-Aldrich), $0.11 \mathrm{~g}$ of sodium hydroxide $(98 \% \mathrm{NaOH}$, Carlo Erba), and $7 \mathrm{ml}$ of deionized (DI) water were mixed and stirred at room temperature for $1 \mathrm{~h}$. Then, the desired amount of TPOAC was dropped slowly into the solution. The final molar composition was $178 \quad \mathrm{SiO}_{2} / 1 \quad \mathrm{Al}_{2} \mathrm{O}_{3} / 16 \quad \mathrm{NaO}_{2} / 9 \quad \mathrm{TPABr} / 4251 \mathrm{H}_{2} \mathrm{O} / x \quad \mathrm{TPOAC}$, which $x$ refers to the amount of TPOAC. The mixture was stirred further for $2 \mathrm{~h}$ and transferred to a Teflon-coated stainless steel autoclave. Then, it was heated at $453 \mathrm{~K}$ for 3 days. The product was filtered and washed with deionized water until the $\mathrm{pH}$ of filtrate less than 9. It was then dried in an oven at $373 \mathrm{~K}$ overnight and subsequently calcined in air at $823 \mathrm{~K}$ for $9 \mathrm{~h}$. The obtained samples were designated as ZSM-5_( $x$ )TPOAC in which $x$ refers to an amount of TPOAC in molar composition. To compare the benefits of modified and unmodified structures, a conventional sample, the ZSM-5 was also synthesized in the absence of TPOAC and the commercial ZSM-5 (SH-55 from ALSIPENTA Zeolithe $\mathrm{GmbH}, \mathrm{Si} / \mathrm{Al}$ ratio of 24) was also used to compare with the synthesized samples. They are designated as C_ZSM-5 and Commercial ZSM-5, respectively. 
To prepare the acid catalyst, all synthesized samples were ion-exchanged into the proton-formed ZSM-5 by repeating the treatment three times with $1 \mathrm{M}$ of $\mathrm{NH}_{4} \mathrm{NO}_{3}$ at $353 \mathrm{~K}$ for $2 \mathrm{~h}$. Then, the sample was dried at $373 \mathrm{~K}$ and calcined at $823 \mathrm{~K}$ for $6 \mathrm{~h}$.

To evaluate the influence of the number of acid sites, we therefore prepared the hierarchical ZSM-5 samples with various $\mathrm{Si} / \mathrm{Al}$ ratios. For a typical synthesis, the above-mentioned procedure with varying the amount of sodium aluminate was used. The amount of $\mathrm{Al}_{2} \mathrm{O}_{3}$ was varied in the range of 1 to 3.6 molar ratio. The samples are designated as Hierarchical ZSM5(A) in which A refers to the $\mathrm{Si} / \mathrm{Al}$ ratio.

To compare the effect of hierarchical structures obtained by different synthesis approaches on their catalytic performances, an alkaline post treatment was also chosen for the preparation of hierarchical ZSM-5 as a representative of a top-down synthesis approach. A $1 \mathrm{~g}$ of the commercial zeolite (SH-55 from ALSIPENTA Zeolithe $\mathrm{GmbH}, \mathrm{Si} / \mathrm{Al}$ ratio of 24) was mixed with $30 \mathrm{ml}$ of $0.5 \mathrm{M} \mathrm{NaOH}$ and it was stirred at $353 \mathrm{~K}$ for $1 \mathrm{~h}$. Then, the product was washed with DI water until the $\mathrm{pH}$ of filtrate less than 8. The filtered product was dried and subsequently ionexchanged into the proton-formed catalyst. The alkaline treated sample is designated as the Hierarchical ZSM-5_AT.

\section{Characterization of catalysts}

Powder X-ray diffraction (XRD) patterns were recorded by a Bruker D8 ADVANCE instrument using $\mathrm{CuK} \alpha$ radiation $(30 \mathrm{kV}, 40 \mathrm{~mA})$ with step size of $0.02^{\circ}$ and scan rate of $10^{\circ} \mathrm{min}^{-1}$ in the $2 \theta$ range of $5-50^{\circ}$. The relative crystallinity of zeolite samples was calculated by the following equation: (\% XRD relative crystallinity of the desired sample $=(\mathrm{Hx} / \mathrm{Hr}) \times 100)$, where $\mathrm{Hx}$ and $\mathrm{Hr}$ are the height of the most intense peak for the desired samples and the reference sample, respectively. The morphologies of materials were examined by a scanning electron microscopy (SEM) performed with a Hitachi-3400 instrument. The samples for SEM studies were dispersed on carbon tape and coated with a thin layer of gold.

Nitrogen adsorption-desorption isotherms were measured at $77 \mathrm{~K}$ performed on a Micromeritics ASAP 2020 physisorption analyzer. Before the measurement, the samples were evacuated at $575 \mathrm{~K}$ for $20 \mathrm{~h}$. The specific surface area was calculated by using the Brunauer-Emmett-Teller (BET) theory $\left(S_{\mathrm{BET}}\right) .{ }^{48}$ The total pore volume $\left(V_{\text {tot }}\right)$ was calculated at $P / P_{0}=0.98$. The $t$-plot method was used to calculate the micropore volume $\left(V_{\text {micro }}\right)$, and external surface area $\left(S_{\text {ext }}\right){ }^{49}$ The mesopore size distributions were examined by using the Barrett-Joyner-Halenda (BJH) model derived from the adsorption branch of isotherms. ${ }^{50}$

The aluminum structures were determined by using ${ }^{27} \mathrm{Al}$ MAS NMR spectroscopy performed on an AVANCE $300 \mathrm{MHz}$ Digital NMR spectrometer (Bruker Biospin; DPX-300) at 78 $\mathrm{MHz}$. The $\mathrm{Al}_{2} \mathrm{O}_{3}$ was used as a reference (set to $0 \mathrm{ppm}$ ). The $\mathrm{Si} / \mathrm{Al}$ ratio of products was investigated by ICP-OES technique performed on the Agilent Technologies 715 model.

The $\mathrm{NH}_{3}$ temperature-programmed desorption ( $\mathrm{NH}_{3}$-TPD) curves were recorded by using a fixed-bed reactor system equipped with a TCD detector. Typically, a $1 \mathrm{~g}$ of zeolite sample was pretreated at $823 \mathrm{~K}$ for $2 \mathrm{~h}$ under the flow of $\mathrm{N}_{2}(30 \mathrm{ml}$ $\min ^{-1}$ ) and it was subsequently cooled down to $323 \mathrm{~K}$. The sample was equilibrated with 5 vol\% of $\mathrm{NH}_{3}$ in He for $60 \mathrm{~min}$ and then purged under the flow of $\mathrm{He}\left(30 \mathrm{ml} \mathrm{min}^{-1}\right)$ for $1 \mathrm{~h}$. To record $\mathrm{NH}_{3}$ TPD profiles, the temperature was increased from $323 \mathrm{~K}$ to $1073 \mathrm{~K}$ with the heating rate of $10 \mathrm{~K} \mathrm{~min}^{-1}$. To determine the density of acid sites in zeolites, FTIR spectra of pyridine adsorption were recorded at a $2 \mathrm{~cm}^{-1}$ resolution and averaged over 64 scans performed on a Bruker Vertex V70v instrument. Firstly, the zeolite sample was heated to $823 \mathrm{~K}$ with the heating rate of $2 \mathrm{~K} \mathrm{~min}^{-1}$ under 20 vol\% $\mathrm{O}_{2}$ in He. Pyridine was then introduced for $10 \mathrm{~min}$ into the chamber at its vapor pressure at room temperature. Subsequently, pyridine was removed by evacuation for $1 \mathrm{~h}$ at $573 \mathrm{~K}$. To calculate the number of Brønsted and Lewis acid sites, molar extinction coefficient

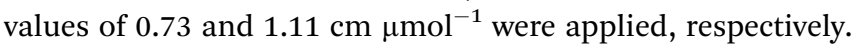

The amount of coke formation in the zeolite network after catalytic tests was evaluated by the thermogravimetric analysis (TGA) and the $\mathrm{O}_{2}$ temperature-programmed desorption $\left(\mathrm{O}_{2}\right.$ TPO). As for TGA experiments, it was performed on a Perkin Elmer Pyris 1 TGA instrument in the temperature range of 373$1073 \mathrm{~K}$ with a heating rate of $10 \mathrm{~K} \mathrm{~min}^{-1}$ under an oxygen $\left(\mathrm{O}_{2}\right.$, 99.99\% purity, Praxair, Thailand) with the flow rate of $40 \mathrm{ml}$ $\min ^{-1}$. Prior to the $\mathrm{O}_{2}$-TPO measurement, used catalysts were pretreated at $523 \mathrm{~K}$ for $2 \mathrm{~h}$ under the flow of He. The catalysts were then heated under the flow of $5 \%(\mathrm{v} / \mathrm{v}) \mathrm{O}_{2}$ in He. The TPO profiles were recorded in the temperature range of 373-1073 K with the ramp rate of $5 \mathrm{~K} \mathrm{~min}^{-1}$. The Raman spectra of spent catalysts were collected at room temperature, performing at least 3 different positions. A laser beam was used at $532 \mathrm{~nm}$ focused on the sample by a microscope.

\section{Esterification of benzyl alcohol with acetic acid}

Prior to the catalytic test, the proton-formed ZSM-5 samples were activated at $823 \mathrm{~K}$ for $6 \mathrm{~h}$. For the experimental procedure, the reaction was performed in a three-necked round bottom flask with a reflux condenser at $373 \mathrm{~K}$ under an atmospheric pressure. A $15 \mathrm{ml}$ of toluene was added into the reactor following by $0.10 \mathrm{ml}$ of decane as a solvent and an internal standard, respectively. A $3.10 \mathrm{ml}$ of benzyl alcohol and $2.06 \mathrm{ml}$ of acetic acid were added. A $0.45 \mathrm{~g}$ of catalyst was then placed into the reactor. The reaction mixtures were collected at a desired time and analyzed by gas chromatography (GC) performed on an Agilent 7820A GC instrument using a FID detector and a DB- 1 capillary column $(100 \mathrm{~m} \times 0.5 \mu \mathrm{m} \times 0.25 \mathrm{~mm})$. The percentage of conversion was calculated based on the total percentage of benzyl alcohol converted into the product. The quantitative analysis was investigated by using the individual calibration curves of benzyl alcohol and its products as shown in Fig. S1 in ESI. $\dagger$ The mass balance was checked for all experiments $(97.29 \pm 1.50 \%)$.

\section{Results and discussion}

\section{Characterization of catalysts}

Effect of TPOAC content. According to the XRD results in Fig. 1, the patterns reveal that all samples contain characteristic 


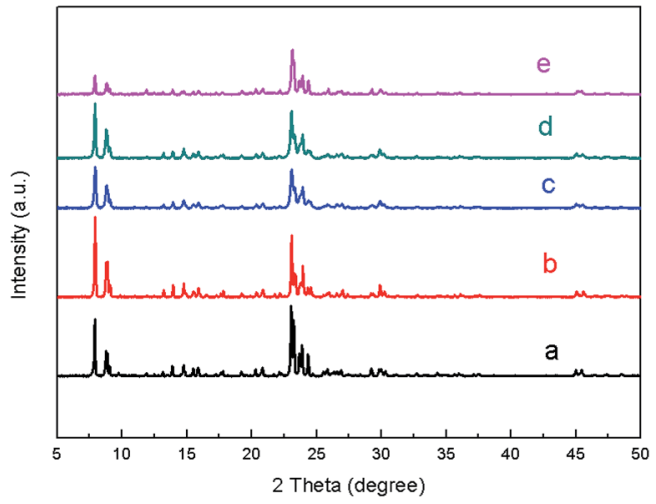

Fig. 1 XRD patterns of all ZSM-5 samples obtained at various TPOAC contents: (a) Commercial ZSM-5, (b) C_ZSM-5, (c) ZSM-5_(4.8) TPOAC, (d) ZSM-5_(9.6)TPOAC, and (e) ZSM-5_(38.4)TPOAC.

peaks of the MFI zeolite structure with high crystallinity, while no crystalline impurity phase is observed. It suggests that zeolite samples were successfully synthesized under a simple hydrothermal process even in the presence of a mesopore structure-directing agent. For example, the samples obtained by adding a small amount of TPOAC (ZSM-5_(4.8)TPOAC and ZSM5_(9.6)TPOAC) exhibit high intense peaks comparable to the reference sample (C_ZSM-5), having the relative crystallinity of $61.5 \%$ and $69.5 \%$, respectively (see Table S1 in the ESI†े). However, when the TPOAC was further added with higher content, the relative crystallinity of samples, ZSM-5_(38.4) TPOAC, is significantly decreased (about 40\%). A large amount of surfactant directly causes the significant reduction of crystallinity, suggesting the incompatibility of surfactant and zeolite gels to hinder the crystallization process (from 9.6 to $38.4 \mathrm{~mol}$ of TPOAC). This makes it clear that the amount of a mesoporous structure-directing agent strongly affects the formation of zeolite structures.

To verify the morphologies of synthesized zeolites, the scanning electron microscopy (SEM) images reveal that the TPOAC apparently affects the morphology of products (Fig. 2). In the absence of TPOAC, the C_ZSM-5 sample exhibits smooth surface morphology, having particle sizes of $3.6 \pm 0.5 \mu \mathrm{m}$ (see the particle size distribution in Fig. S2 in the ESI $†$ ). In strong contrast to this, the sample obtained in the presence of low TPOAC content, ZSM-5_(4.8)TPOAC, shows non-uniform particles with various shapes, including coffin-like and spherical morphologies. Due to the variety of shapes and non-uniform particle size distribution $(8.8 \pm 2.0 \mu \mathrm{m}$ see in Fig. S2 in the ESI $\dagger$ ), this would allow us to increase the TPOAC content to produce more uniform particles. Consequently, the ZSM-5_(9.6) TPOAC product was fabricated by increasing the amount of TPOAC. The sample exhibits stacking plate-like shapes, providing a high surface areas with average crystal sizes of 10.6 $\pm 2.0 \mu \mathrm{m}$ (Fig. S2 in the ESI $\dagger$ ). To examine the limitation of TPOAC content, the ZSM-5_(38.4)TPOAC was also synthesized by further increasing the amount of TPOAC by the fourfold compared with the ZSM-5_(9.6)TPOAC. The mixture of crystalline and amorphous phases is observed, when an excess amount of TPOAC is added. This is consistent with the XRD
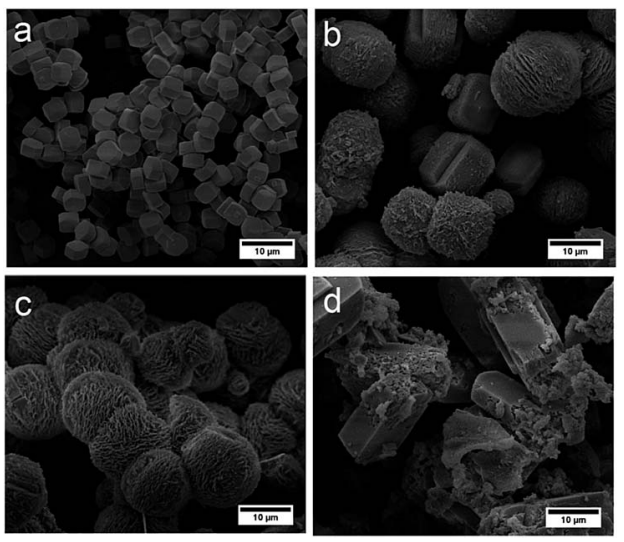

Fig. 2 SEM images of ZSM-5 samples obtained at various amounts of TPOAC: (a) C_ZSM-5, (b) ZSM-5_(4.8)TPOAC, (c) ZSM-5_(9.6)TPOAC, and (d) ZSM-5_(38.4)TPOAC.

data, showing a dramatic decrease in crystallinity compared with the reference sample (C_ZSM-5). In particular, the simultaneous presence of the coffin-like crystals and the amorphous phase is observed in the case of the ZSM-5_(38.4)TPOAC sample due to the use of overdosed TPOAC.

To confirm the presence of mesoporosity, the textural properties of all samples were measured by $\mathrm{N}_{2}$ physisorption technique. $\mathrm{N}_{2}$ adsorption/desorption isotherms (Fig. 3) demonstrate that synthesized ZSM-5 products show the isotherms with hysteresis loop at $P / P_{0}$ in the range of $0.4-0.8$ due to the mesopore filling, indicating the presence of additional mesopores. In contrast to the synthesized samples, the hysteresis loop does not exist in the isotherm of the commercial ZSM-5 and the C_ZSM-5, while the adsorption at the relatively low pressure $\left(P / P_{0} \sim 0.2\right)$ with a long horizontal plateau is clearly observed due to the micropore filling, suggesting the presence of sole micropores in the zeolite structure. Moreover, the $\mathrm{BJH}$ mesopore size distribution in Fig. 4 reveals the presence of a mesoporous structure in the hierarchical ZSM-5 samples. The BJH curve of ZSM-5_(9.6)TPOAC sample shows a wide distribution in the range of $10-20 \mathrm{~nm}$. However, when the TPOAC is

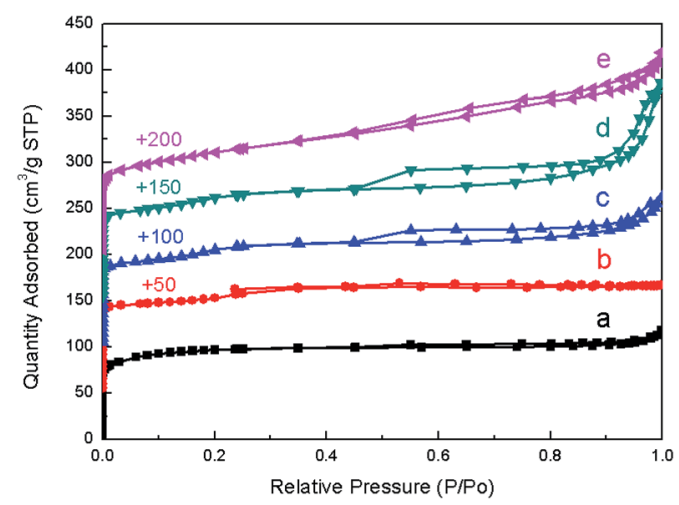

Fig. $3 \quad \mathrm{~N}_{2}$ adsorption/desorption isotherms of synthesized ZSM-5 samples obtained at various TPOAC contents: (a) Commercial ZSM-5, (b) C_ZSM-5, (c) ZSM-5_(4.8)TPOAC, (d) ZSM-5_(9.6)TPOAC, and (e) ZSM-5_(38.4)TPOAC. 


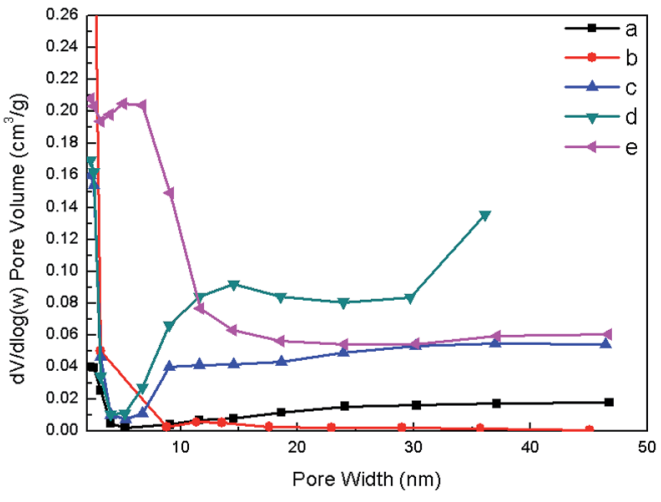

Fig. 4 Mesopore size distribution derived from $\mathrm{BJH}$ adsorption branch of synthesized ZSM-5 samples obtained at various TPOAC contents: (a) Commercial ZSM-5, (b) C_ZSM-5, (c) ZSM-5_(4.8)TPOAC, (d) ZSM5_(9.6)TPOAC, and (e) ZSM-5_(38.4)TPOAC.

increased to $38.4 \mathrm{~mol}$, the pore size distribution becomes narrow in the range of $5-10 \mathrm{~nm}$. In contrast, the porous structure in the range of mesopore size was not observed in the cases of the commercial ZSM-5 and the C_ZSM-5. This result again confirms the presence of hierarchical mesopores in the hierarchical ZSM-5 samples and the presence of sole micropores in the conventional ZSM-5, which is consistent with the $\mathrm{N}_{2}$ sorption isotherm results.

From these observations, the results indicate that a suitable amount of TPOAC is equal to $9.6 \mathrm{~mol}$, which produces excellent textural properties (Table 1), providing the highest mesoporosity. It is therefore reasonable to assume that in the case of the catalytic study, it should be possible to be used as a candidate catalyst.

\section{Effect of $\mathrm{Si} / \mathrm{Al}$ ratios}

To verify the role of acidity on the catalytic performances, we also carried out several additional experiments to prepare the hierarchical ZSM-5 samples with various $\mathrm{Si} / \mathrm{Al}$ ratios via a direct synthesis. The catalysts, having low $\mathrm{Si} / \mathrm{Al}$ ratio, $\mathrm{Si} / \mathrm{Al}=34$ (hierarchical ZSM-5(34)), and high Si/Al ratio, Si/Al = 90, (ZSM5_(9.6)TPOAC or hierarchical ZSM-5(90)), were also synthesized by using the suitable amount of TPOAC obtained from the previous section to generate secondary mesopores. The hierarchical ZSM-5(34) also shows characteristic peaks of the MFI
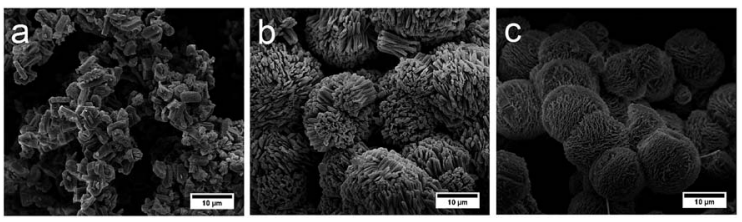

Fig. 5 SEM images of: (a) Commercial ZSM-5, and (b) Hierarchical ZSM-5(34), the representative sample having low Si/Al ratio: (c) Hierarchical ZSM-5(90), the representative sample having high Si/Al ratio.

structure as shown in Fig. S3 in the ESI. $\uparrow$ However, its crystallinity is lower than that of the commercial ZSM-5 due to the effect of TPOAC template on the morphology of crystal growth. SEM images in Fig. 5 also confirm the differences in morphologies of three catalysts, the commercial ZSM-5, the hierarchical ZSM-5(34), and the hierarchical ZSM-5(90). Interestingly, the hierarchical ZSM-5(34) sample exhibits the self-assemblies of stick-like nanocrystals, while the hierarchical ZSM-5(90) sample consists of stacking plate-like crystals. Both samples are expected to show high catalytic performance due to their high surface areas and mesoporosity as shown in Table 1.

In addition to the number of acid sites, the nature of $\mathrm{Al}$ sites was also monitored by ${ }^{27} \mathrm{Al}$ MAS NMR spectroscopy (as shown in Fig. S4 in the ESI $\dagger$ ). As the presence of the single peak at about 54 ppm of all samples, it clearly shows that the samples contain only tetrahedral coordinated $\mathrm{Al}$ in frameworks, whereas the presence of the octahedrally extra-framework $\mathrm{Al}$ species can be excluded.

The acidity of catalysts was also examined by $\mathrm{NH}_{3}$-TPD technique. From $\mathrm{NH}_{3}$-TPD profiles (Fig. 6), all curves were fitted and obtained with two visible peaks, appearing at low temperature, LT ( ca. $493 \mathrm{~K}$ ) and high temperature, HT (ca. $723 \mathrm{~K})$. The LT peak is assigned to weak acid sites due to the interaction between $\mathrm{NH}_{3}$ molecules desorbed from weakly acidic hydroxyl sites, which also refer to the defect and external silanol groups. However, the HT peak corresponds to the desorption of $\mathrm{NH}_{3}$ from strong acid sites, which are Brønsted acid sites (BAS) and Lewis acid sites (LAS). ${ }^{51}$ Among synthesized samples, the hierarchical ZSM-5(34) sample exhibits the lower acidity, which is of $35.5 \%$ compared with the commercial ZSM-5. As expected, the hierarchical ZSM-5(90) shows the lowest acidity due to a small number of acid sites and it decreases approximately by $35 \%$

Table 1 Textural properties and Si/Al ratios of all synthesized ZSM-5 samples

\begin{tabular}{|c|c|c|c|c|c|c|c|c|}
\hline Samples & $\mathrm{Si} / \mathrm{Al}^{a}$ & $S_{\mathrm{BET}}^{b}$ & $S_{\text {micro }}{ }^{c}$ & $S_{\mathrm{ext}}^{d}$ & $V_{\text {total }^{e}}^{e}$ & $V_{\text {micro }}^{f}$ & $V_{\text {ext/meso }}^{g}$ & $V_{\text {meso }} / V_{\text {total }}^{h}$ \\
\hline Commercial ZSM-5 & 19 & 363 & 276 & 87 & 0.171 & 0.110 & 0.060 & 0.351 \\
\hline C_ZSM-5 & 115 & 387 & 249 & 137 & 0.180 & 0.099 & 0.081 & 0.450 \\
\hline ZSM-5_(9.6)TPOAC & 90 & 396 & 176 & 220 & 0.346 & 0.072 & 0.273 & 0.789 \\
\hline ZSM-5_(38.4)TPOAC & 97 & 393 & 163 & 229 & 0.321 & 0.068 & 0.253 & 0.788 \\
\hline Hierarchical ZSM-5(34) & 34 & 434 & 287 & 147 & 0.338 & 0.115 & 0.223 & 0.660 \\
\hline
\end{tabular}

${ }^{a} \mathrm{Si} / \mathrm{Al}$ ratio obtained by ICP-OES technique. ${ }^{b} S_{\mathrm{BET}}$ : BET specific surface area. ${ }^{c} S_{\text {micro }}$ : micropore surface area. ${ }^{d} S_{\text {ext }}:$ external surface area. ${ }^{e} V_{\text {total }}$ : total pore volume. ${ }^{f} V_{\text {micro: }}$ : micropore volume. ${ }^{g} V_{\text {ext/meso }}=V_{\text {total }}-V_{\text {micro }}$; all surface areas and pore volumes are in the units of $\mathrm{m}^{2} \mathrm{~g}^{-1}$ and $\mathrm{cm}^{3} \mathrm{~g}^{-1}$, respectively. ${ }^{h}$ Fraction of mesopore volume. 


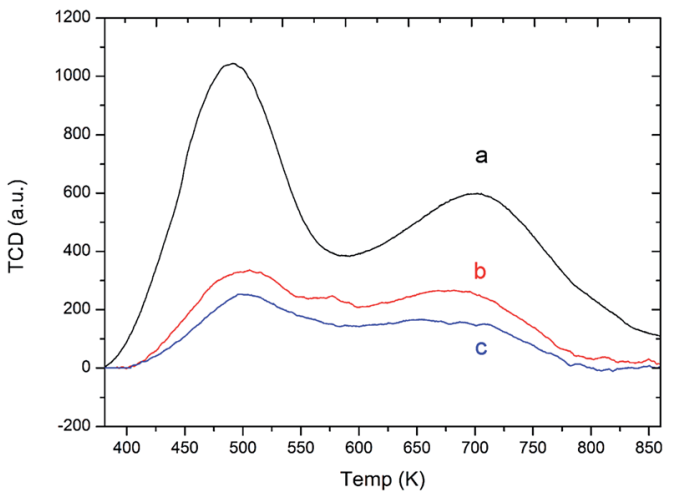

Fig. $6 \mathrm{NH}_{3}$-TPD curves obtained on different samples: (a) Commercial ZSM-5, (b) Hierarchical ZSM-5(34), and (c) Hierarchical ZSM-5(90).

compared with the hierarchical ZSM-5(34) sample. The amount of acid sites is known to relate to $\mathrm{Al}$ atoms in a framework in which the charge is compensated by acidic protons. ${ }^{52}$

To further investigate the amount of BAS and LAS, FTIR spectra of pyridine adsorption are shown in Fig. S5 and Table $\mathrm{S} 2 . \dagger$ The peak at around $1545 \mathrm{~cm}^{-1}$ is assigned to pyridinium ions formed by protonation at BAS, while a band at $1455 \mathrm{~cm}^{-1}$ corresponds to pyridine adsorbed on LAS. It was found that the contribution of BAS of both catalysts is very high compared with LAS. This parameter strongly affects many potential catalytic applications, especially in an esterification. ${ }^{53}$ Consequently, this catalyst is expected to lead to enhancing the catalytic activity of the esterification.

\section{Catalytic performance of catalysts}

To illustrate the benefits of hierarchical catalysts for the catalytic upgrading of carboxylic acids, the prepared samples were tested with an esterification of benzyl alcohol and acetic acid as a model study (as shown in Scheme 1). As shown in Fig. 7, the catalytic activities of an esterification of different catalysts are demonstrated as a function of reaction time. The major product of this reaction is benzylacetate, which is almost $100 \%$ selectivity for all catalysts (Fig. 7). Interestingly, the hierarchical ZSM-5(34) sample exhibits an excellent activity compared with the other catalysts. It can convert the reactant into product about $90 \%$ in $8 \mathrm{~h}$. In contrast, the commercial ZSM- 5 shows very low activity, which gives only $22 \%$ of the conversion of alcohol, although it contains higher acidic density compared with the hierarchical ZSM-5(34). The different activities between two catalysts can be attributed to the fact that the presence of the

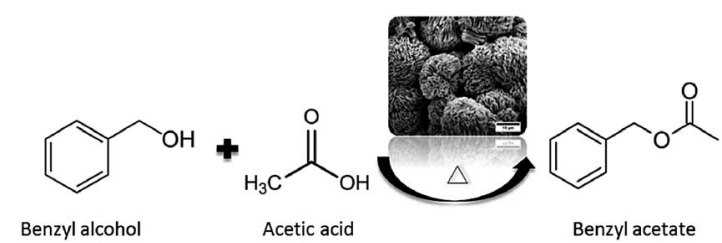

Scheme 1 Esterification reaction of benzyl alcohol and acetic acid on zeolite catalysts.

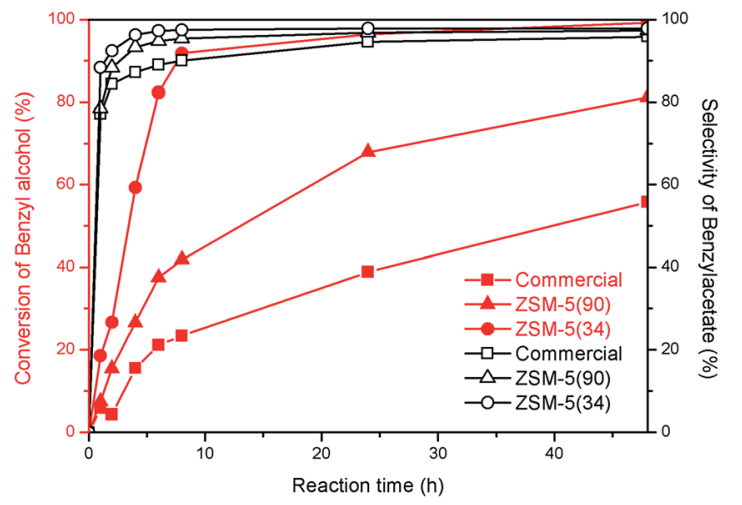

Fig. 7 Benzyl alcohol conversion (\%) (red) and benzylacetate selectivity (\%) (black) as a function of reaction time on different samples: Commercial ZSM-5, Hierarchical ZSM-(90), and Hierarchical ZSM5(34).

hierarchical porous network can reduce the diffusion constraints inside micropores. Interestingly, the hierarchical sample containing the lower amount of acidic density (high $\mathrm{Si}$ / Al ratio) also exhibits higher catalytic activity than that of the commercial ZSM-5, implying that the higher catalytic activity can be contributed by the hierarchical porous network. This result again confirms that the promising property of hierarchical structures can promote the catalytic activity of an esterification of carboxylic acid.

To demonstrate the efficiency of catalysts, the reusability studies of the hierarchical ZSM-5 and the corresponding conventional zeolite were also carried out at various reaction cycles (Fig. 8). The conversion of alcohol is about $90 \%$ at $8 \mathrm{~h}$ when the hierarchical ZSM-5(34) sample was used as a catalyst for the first cycle. In contrast, the commercial sample only converts the reactant into the product by $22 \%$. For the second cycle, the hierarchical ZSM-5(34) sample still exhibits an excellent performance by showing about $85 \%$ of alcohol conversion. However, the commercial catalyst performs similarly low catalytic activity compared to itself in the first cycle. In the third cycle, the hierarchical catalyst still shows, as expected, a good catalytic performance ( $80 \%$ conversion of alcohol), while the

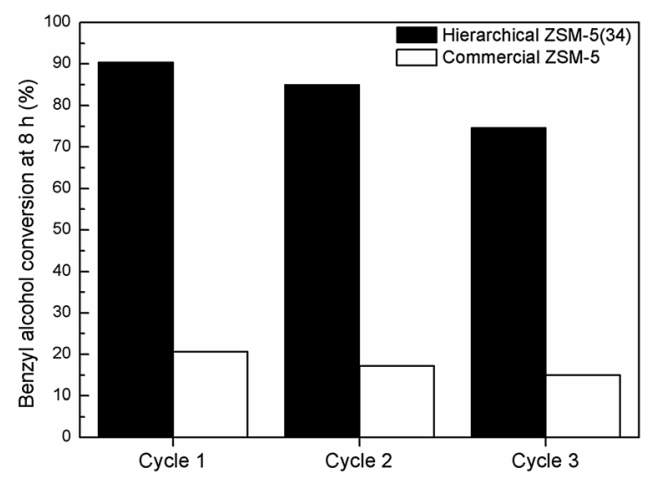

Fig. 8 Reusability experiments of Hierarchical ZSM-5(34) and Commercial ZSM-5 catalysts for three cycles (catalytic test condition: $373 \mathrm{~K}$ and $1 \mathrm{~atm})$. 
commercial one only converts about $15 \%$ of the alcohol toward the product. It is noteworthy that the inferior catalytic activity of the commercial sample is due to the presence of sole micropores in the structure and this could eventually lead to accelerate the coke formation.

To further verify in the term of catalyst deactivation, the amount of deposited coke was also measured by the temperature thermogravimetric analysis (TGA) and the $\mathrm{O}_{2}$ temperatureprogrammed oxidation $\left(\mathrm{O}_{2}-\mathrm{TPO}\right)$ as shown in Fig. $\mathrm{S} 6$ and $\mathrm{S} 7$ in the ESI. $\dagger$ From TGA profiles, it was found that a carbon weight loss over the hierarchical ZSM-5(34) sample is much less than that of the commercial one $(11.5 \%$ and $32.4 \%$ for the hierarchical ZSM-5(34) and the commercial ZSM-5, respectively) after the reaction time of $24 \mathrm{~h}$. As expected, the presence of hierarchical pores obviously improves the catalytic activity by rendering molecular transportation, resulting in a reduction in coke formation.

In contrast, the commercial sample contains a large amount of deposited coke due to the presence of sole micropores in its structure, causing the pore blocking. Besides, $\mathrm{O}_{2}$-TPO profiles demonstrate the location and the type of carbonaceous species. At the low temperature about $673 \mathrm{~K}$, it is attributed to the lowest aromatic condensation, which are easily oxidized and mostly located on the outermost surface of zeolite (coke I). Meanwhile, at higher temperature about $773-873 \mathrm{~K}$, it is ascribed to the high aromatic condensation, the polynuclear aromatic coke species or graphitic like coke (cokes II and III), which are originated from the microporous zeolite structure..$^{54-56}$ The deconvolution of TPO curves shows an amount of coke content of three different species. The significant decrease of cokes I and II over the hierarchical ZSM-5 sample was observed, indicating a lower degree of condensation of coke species. The commercial sample exhibits a large amount of developed polynuclear aromatic coke/ graphitic species deposited on external surfaces and inside zeolite structures with the total coke content of $10 \mathrm{mmol} \mathrm{g}^{-1}$. In contrast, the hierarchical ZSM-5 sample dramatically reduces the coke formation of all types with the total coke content of $3 \mathrm{mmol} \mathrm{g}^{-1}$ due to shortening the diffusion path length. On the other hand, a large content of coke II and III species in the commercial sample indicates that the fast deactivation of catalyst is the results of pore blockage by high aromatic condensation. This is also consistent with the TGA results, revealing that the hierarchical samples can significantly reduce the content, resulting in an increase of catalytic activity. Fig. $\mathrm{S} 8 \dagger$ shows Raman spectra of coke species deposited on catalysts after the reaction. It was found that two visible peaks appearing at 1610 and $1389 \mathrm{~cm}^{-1}$ are assigned to the $\mathrm{G}$ band corresponding to the presence of graphitic materials ${ }^{57}$ and the $\mathrm{D}$ band due to disordered carbon structures, respectively. Obviously, both catalysts exhibit the presence of both graphite-like carbon species and disordered amorphous polyaromatic species. Interestingly, the ratio of area of $\mathrm{D}$ band and $\mathrm{G}$ band $\left(I_{\mathrm{D}} / I_{\mathrm{G}}\right)$ of commercial ZSM-5 and hierarchical ZSM-5(34) is 0.52 and 0.39 , respectively. These correspond well with $\mathrm{O}_{2}$-TPO results that the higher ratio of coke II to coke III content was observed in the deposited coke obtained by a commercial catalyst.
This makes it clear that the catalytic activity for the esterification of carboxylic acids can be greatly improved in the case of hierarchical ZSM-5 samples even though they exhibit lower Brønsted acid density. Together with the presence of mesoporous networks connected to the microporous framework, it gives the benefits to improve the catalytic performances in terms of catalytic activity, desired product yield, and catalyst stability/reusability, due to the improved accessibility to active sites. On the other hand, the sole microporous structure of commercial ZSM- 5 does not show the advantage for the reaction because of not only inhibiting the diffusion of molecules to active sites but also facilitating the coke formation inside microporous network, especially for catalysts with very high Brønsted acid density, which is required for the acid catalysed reaction, such as an esterification of organic acids.

To compare the catalytic performances of hierarchical zeolites obtained by various synthesis approaches (Fig. S9 in the ESI $\uparrow$ ), the hierarchical ZSM-5 sample obtained by a direct synthesis, hierarchical ZSM-5(34), shows a significantly improved catalytic activity compared with those obtained by using a conventional alkaline treatment, even though both samples contain the similarity in textural properties, such as micro- and mesoporosity (as shown in Table $\mathrm{S} 3$ in the ESI†). The hierarchical ZSM-5(34) sample exhibits an excellent conversion of alcohol (about 90\% and high selectivity of benzylacetate almost $100 \%)$.

In order to further illustrate the benefits of hierarchical zeolites for the catalytic upgrading of carboxylic acids, an esterification of levulinic acid, which can be formed by the acidcatalyzed dehydration of monosaccharide, and ethanol has also been investigated (Table S4 in the ESI $\dagger$ ). Interestingly, the hierarchical zeolite can greatly improve the catalytic activity to produce the ethyl levulinate that can be used as diesel miscible biofuel (DMB). The hierarchical ZSM-5 have the two-three fold advantage of the catalytic conversion of levulinic acid compared with the conventional zeolite as well as preserved shape selectivity of zeolite framework. This work opens up interesting perspectives for the development of hierarchical mesoporous zeolites via a direct synthesis approach using an organosilane template for the catalytic upgrading of various carboxylic acids.

\section{Conclusions}

The hierarchical ZSM-5 samples have been successfully synthesized under a simple direct hydrothermal method. With the aid of TPOAC, the synthesized hierarchical ZSM-5 products exhibit promising catalytic performances in terms of increasing activity, desired product yield, and catalyst reusability for an esterification of carboxylic acids. In particular, the hierarchical ZSM-5(34) sample performs a remarkable activity by converting almost $90 \%$ of benzylalcohol to benzylacetate for an esterification of acetic acid and benzylalcohol within $8 \mathrm{~h}$ corresponding to the presence of hierarchical porous networks in the zeolite structure.

To illustrate the ability of hierarchical structures, the sample with a low content of acidic density also shows a good performance by catalyzing $70 \%$ of reactant in $24 \mathrm{~h}$. This might be 
explained by the hierarchical pores rendering the catalyst's performance. In the view of catalyst reusability, the hierarchical catalyst, hierarchical ZSM-5(34), exhibits an excellent performance compared with the commercial catalyst with almost fivefold catalytic activity even after three cycles.

To evaluate the efficiency of catalysts obtained by different synthesis methods, it was also found that the catalyst prepared by a direct synthesis shows a significantly improved activity compared with the one obtained by a conventional posttreatment method. Interestingly, not only different catalytic performances can be observed for hierarchical zeolites obtained by different methods, but also a wider range of framework $\mathrm{Si} / \mathrm{Al}$ ratios of catalysts can be prepared by a direct synthesis. For these reasons, the developed hierarchical zeolites by a direct synthesis approach can benefit to many applications, in particular, the bio-oil upgrading via an esterification of various carboxylic acids for the development of renewable energy resources in future.

\section{Acknowledgements}

This work was supported in part by grants from the National Science and Technology Development Agency (NANOTEC Center for Nanoscale Materials Design for Green Nanotechnology funded by the National Nanotechnology Center), the Commission on Higher Education, Ministry of Education (the National Research University Project of Thailand), the Vidyasirimedhi Institute of Science and Technology, the PTT group (PTT Public Company Limited, PTT Exploration \& Production, PTT Global Chemical, IRPC and Thaioil). K. R. would like to thank to the Development and Promotion of Science and Technology Talents Project (DPST). C. W. would like to acknowledge funding from the Thailand Research Fund (TRF) (MRG5980114), the Office of Higher Education Commission (OHEC), the Junior Research Fellowship Program of the French Embassy in Thailand, and the support of scientific instrument by the Frontier Research Center, Vidyasirimedhi Institute of Science and Technology and Schuit Institute of Catalysis, Department of Chemical Engineering and Chemistry, Eindhoven University of Technology.

\section{References}

1 M. Stöcker, Angew. Chem., Int. Ed., 2008, 47, 9200-9211.

2 H. B. Goyal, D. Seal and R. C. Saxena, Renewable Sustainable Energy Rev., 2008, 12, 504-517.

3 S. Czernik and A. V. Bridgwater, Energy Fuels, 2004, 18, 590598.

4 P. M. Mortensen, J. D. Grunwaldt, P. A. Jensen, K. G. Knudsen and A. D. Jensen, Appl. Catal., A, 2011, 407, 1-19.

5 C. A. Gärtner, J. C. Serrano-Ruiz, D. J. Braden and J. A. Dumesic, ChemSusChem, 2009, 2, 1121-1124.

6 R. W. Snell, E. Combs and B. H. Shanks, Top. Catal., 2010, 53, 1248-1253.

7 Y. Liu, Z. Li, J. J. Leahy and W. Kwapinski, Energy Fuels, 2015, 29, 3691-3698.
8 L. Ciddor, J. A. Bennett, J. A. Hunns, K. Wilson and A. F. Lee, J. Chem. Technol. Biotechnol., 2015, 90, 780-795.

9 S. Furuta, H. Matsuhashi and K. Arata, Catal. Commun., 2004, 5, 721-723.

10 E. Cano-Serrano, G. Blanco-Brieva, J. M. Campos-Martin and J. L. G. Fierro, Langmuir, 2003, 19, 7621-7627.

11 H. Liu, N. Xue, L. Peng, X. Guo, W. Ding and Y. Chen, Catal. Commun., 2009, 10, 1734-1737.

12 A. Corma, H. Garcia, S. Iborra and J. Primo, J. Catal., 1989, 120, 78-87.

13 J. Bedard, H. Chiang and A. Bhan, J. Catal., 2012, 290, 210219.

14 H. Katsuno, T. Fukunaga and M. Sugimoto, in Studies in Surface Science and Catalysis, ed. F. Solymosi, L. Guczi and P. Tétényi, Elsevier, 1993, vol. 75, pp. 2419-2422.

15 W. Wannapakdee, C. Wattanakit, V. Paluka, T. Yutthalekha and J. Limtrakul, RSC Adv., 2016, 6, 2875-2881.

16 P. Cañizares, A. de Lucas, F. Dorado and D. Pérez, Appl. Catal., A, 2000, 190, 233-239.

17 C. Wattanakit, S. Nokbin, B. Boekfa, P. Pantu and J. Limtrakul, J. Phys. Chem. C, 2012, 116, 5654-5663.

18 C. H. Christensen, K. Johannsen, I. Schmidt and C. H. Christensen, J. Am. Chem. Soc., 2003, 125, 13370-13371.

19 P. Wuamprakhon, C. Wattanakit, C. Warakulwit, T. Yutthalekha, W. Wannapakdee, S. Ittisanronnachai and J. Limtrakul, Microporous Mesoporous Mater., 2016, 219, 1-9. 20 G. M. Lari, B. Puértolas, M. S. Frei, C. Mondelli and J. PérezRamírez, ChemCatChem, 2016, 8, 1507-1514.

21 S. R. Kirumakki, N. Nagaraju and K. V. R. Chary, Appl. Catal., A, 2006, 299, 185-192.

22 K. H. Chung and B. G. Park, J. Ind. Eng. Chem., 2009, 15, 388392.

23 C. J. H. Jacobsen, C. Madsen, T. V. W. Janssens, H. J. Jakobsen and J. Skibsted, Microporous Mesoporous Mater., 2000, 39, 393-401.

24 W. Chaikittisilp, Y. Suzuki, R. R. Mukti, T. Suzuki, K. Sugita, K. Itabashi, A. Shimojima and T. Okubo, Angew. Chem., Int. Ed., 2013, 52, 3355-3359.

25 P. Kumar, K. V. Agrawal, M. Tsapatsis and K. A. Mkhoyan, Nat. Commun., 2015, 6, 7128.

26 B. M. Weckhuysen and J. Yu, Chem. Soc. Rev., 2015, 44, 70227024.

27 J. C. Groen, T. Bach, U. Ziese, A. M. Paulaime-van Donk, K. P. de Jong, J. A. Moulijn and J. Pérez-Ramírez, J. Am. Chem. Soc., 2005, 127, 10792-10793.

28 D. Verboekend, S. Mitchell, M. Milina, J. C. Groen and J. Pérez-Ramírez, J. Phys. Chem. C, 2011, 115, 14193-14203.

29 H. Mochizuki, T. Yokoi, H. Imai, S. Namba, J. N. Kondo and T. Tatsumi, Appl. Catal., A, 2012, 449, 188-197.

30 I. Schmidt, A. Boisen, E. Gustavsson, K. Ståhl, S. Pehrson, S. Dahl, A. Carlsson and C. J. H. Jacobsen, Chem. Mater., 2001, 13, 4416-4418.

31 A. H. Janssen, I. Schmidt, C. J. H. Jacobsen, A. J. Koster and K. P. de Jong, Microporous Mesoporous Mater., 2003, 65, 5975.

32 M. Y. Kustova, P. Hasselriis and C. H. Christensen, Catal. Lett., 2004, 96, 205-211. 
33 F.-S. Xiao, L. Wang, C. Yin, K. Lin, Y. Di, J. Li, R. Xu, D. S. Su, R. Schlögl, T. Yokoi and T. Tatsumi, Angew. Chem., Int. Ed., 2006, 45, 3090-3093.

34 H. Zhu, Z. Liu, D. Kong, Y. Wang, X. Yuan and Z. Xie, J. Colloid Interface Sci., 2009, 331, 432-438.

35 Y. Cheneviere, F. Chieux, V. Caps and A. Tuel, J. Catal., 2010, 269, 161-168.

36 W. Park, D. Yu, K. Na, K. E. Jelfs, B. Slater, Y. Sakamoto and R. Ryoo, Chem. Mater., 2011, 23, 5131-5137.

37 K. Cho, K. Na, J. Kim, O. Terasaki and R. Ryoo, Chem. Mater., 2012, 24, 2733-2738.

38 M. Choi, H. S. Cho, R. Srivastava, C. Venkatesan, D.-H. Choi and R. Ryoo, Nat. Mater., 2006, 5, 718-723.

39 Z. Zhao, Y. Liu, H. Wu, X. Li, M. He and P. Wu, Microporous Mesoporous Mater., 2009, 123, 324-330.

40 A. J. J. Koekkoek, H. Xin, Q. Yang, C. Li and E. J. M. Hensen, Microporous Mesoporous Mater., 2011, 145, 172-181.

41 L. Wu, V. Degirmenci, P. C. M. M. Magusin, N. J. H. G. M. Lousberg and E. J. M. Hensen, J. Catal., 2013, 298, 27-40.

42 M. Krishnamurthy, K. Msm and C. Kanakkampalayam Krishnan, Microporous Mesoporous Mater., 2016, 221, 23-31.

43 M. Milina, S. Mitchell and J. Pérez-Ramírez, Catal. Today, 2014, 235, 176-183.

44 D. Verboekend and J. Perez-Ramirez, Catal. Sci. Technol., 2011, 1, 879-890.

45 J. C. Groen, J. C. Jansen, J. A. Moulijn and J. Pérez-Ramírez, J. Phys. Chem. B, 2004, 108, 13062-13065.
46 J. C. Groen, J. A. Moulijn and J. Pérez-Ramírez, Microporous Mesoporous Mater., 2005, 87, 153-161.

47 C. Wattanakit, C. Warakulwit, P. Pantu, B. Sunpetch, M. Charoenpanich and J. Limtrakul, Can. J. Chem. Eng., 2012, 90, 873-880.

48 S. Brunauer, P. H. Emmett and E. Teller, J. Am. Chem. Soc., 1938, 60, 309-319.

49 B. C. Lippens and J. H. de Boer, J. Catal., 1965, 4, 319-323.

50 E. P. Barrett, L. G. Joyner and P. P. Halenda, J. Am. Chem. Soc., 1951, 73, 373-380.

51 J. N. Kondo, R. Nishitani, E. Yoda, T. Yokoi, T. Tatsumi and K. Domen, Phys. Chem. Chem. Phys., 2010, 12, 11576-11586.

52 K. Mlekodaj, K. Tarach, J. Datka, K. Góra-Marek and W. Makowski, Microporous Mesoporous Mater., 2014, 183, 54-61.

53 V. N. Shetti, J. Kim, R. Srivastava, M. Choi and R. Ryoo, J. Catal., 2008, 254, 296-303.

54 F. Bauer and H. G. Karge, Characterization II, ed. H. G. Karge and J. Weitkamp, Springer Berlin Heidelberg, Berlin, Heidelberg, 2007, pp. 249-364.

55 I. H. Son, S. J. Lee, I. Y. Song, W. S. Jeon, I. Jung, D. J. Yun, D.-W. Jeong, J.-O. Shim, W.-J. Jang and H.-S. Roh, Fuel, 2014, 136, 194-200.

56 W. B. Widayatno, G. Guan, J. Rizkiana, J. Yang, X. Hao, A. Tsutsumi and A. Abudula, Appl. Catal., B, 2016, 186, 166-172.

57 J. Guo, H. Lou and X. Zheng, Carbon, 2007, 45, 1314-1321. 